JOURNAL of

MAINE MEDICAL CENTER Journal of Maine Medical Center

Volume 4

Issue 1 Winter 2022

Article 5

2022

\title{
Senior Academic Ranks in US Anesthesiology Programs: \\ Differences Between Women and Men and Examination of Independent Factors for Success
}

\author{
Brenda Lee \\ Harvard Medical School
}

Et al.

Follow this and additional works at: https://knowledgeconnection.mainehealth.org/jmmc

Part of the Anesthesiology Commons, Interprofessional Education Commons, Leadership Studies

Commons, Organization Development Commons, and the Other Medicine and Health Sciences Commons

\section{Recommended Citation}

Lee, Brenda; Zahedi, Farhad; Zaimi, Ina; and Schumann, Roman (2022) "Senior Academic Ranks in US Anesthesiology Programs: Differences Between Women and Men and Examination of Independent Factors for Success," Journal of Maine Medical Center. Vol. 4 : Iss. 1 , Article 5.

Available at: https://knowledgeconnection.mainehealth.org/jmmc/vol4/iss1/5 https://doi.org/10.46804/ 2641-2225.1118

The views and thoughts expressed in this manuscript belong solely to the author[s] and do not reflect the opinions of the Journal of Maine Medical Center or MaineHealth.

This Original Research is brought to you for free and open access by Maine Medical Center Department of Medical Education. It has been accepted for inclusion in the Journal of Maine Medical Center by an authorized editor of the MaineHealth Knowledge Connection. For more information, please contact Dina McKelvy mckeld1@mmc.org.

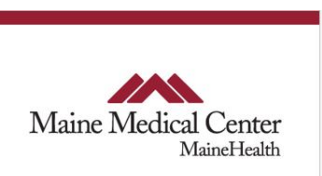


Senior Academic Ranks in US Anesthesiology Programs: Differences Between Women and Men and Examination of Independent Factors for Success

Authors

Brenda Lee, Farhad Zahedi, Ina Zaimi, and Roman Schumann 


\title{
Senior Academic Ranks in US Anesthesiology Programs: Differences Between Women and Men and Examination of Independent Factors for Success
}

\author{
Brenda Lee, MD, ${ }^{1}$ Farhad Zahedi, MD,${ }^{2}$ Ina Zaimi,MD,${ }^{3}$ Roman Schumann, MD, FASA ${ }^{4}$ \\ ${ }^{1}$ Brigham and Woman's Hospital, Department of Anesthesiology, Perioperative and Pain Medicine, Boston, MA, ${ }^{2}$ Tufts \\ Medical Center, Department of Anesthesiology and Perioperative Medicine, Boston, MA, ${ }^{3}$ St. Elizabeth's Medical Center, \\ Department of Anesthesia, Brighton, MA, ${ }^{4}$ VA Boston Healthcare System, Department of Anesthesiology, Critical Care and \\ Pain Medicine, West Roxbury, MA
}

\begin{abstract}
Introduction: Gender equality among faculty is a challenge in academic medicine, including anesthesiology. We investigated the likelihood that several factors were associated with academic success in the United States (US), defined as having achieved a senior academic rank (SAR) in a US anesthesiology training program.
\end{abstract}

Methods:

We collected data available on the Internet on 131 anesthesiology programs, including faculty academic rank, gender, number of faculty, graduate status from an American medical school, fellowship training status, number of residents, number of program fellowships, and geographic location. SAR was defined as either associate professor or professor. Data were analyzed with logistic regression.

Results: $\quad$ We extracted data on 110 programs with complete data of interest available for analysis. These programs represented 7993 faculty, of which $66 \%$ were men and $34 \%$ were women. Within gender subsets, $27.6 \%$ of men vs $18.3 \%$ of women had a SAR, and $13.7 \%$ of men vs $6.6 \%$ of women were professors ( $P \leq .005$ for all comparisons). Female gender, proportionately fewer women faculty, and a larger department were significantly associated with decreased odds of having a SAR. Geographic location influenced the outcome.

Discussion: $\quad$ Program information that was publicly available on the Internet provided meaningful data on factors for academic success in US anesthesiology programs. Female gender, the proportion of women faculty, department size, the number of fellowships in a program, and geographic location were significantly associated with faculty academic success.

Conclusions: This study examined mostly unmodifiable factors influencing academic success and indicates that female gender lessens the odds of success. Efforts are urgently needed to alleviate this gender gap and provide opportunities for improvement.

Keywords: $\quad$ academic success, gender, anesthesiology, equality, faculty

$\mathrm{P}$ ersonal success in academic medicine may be indicated by an advanced academic faculty rank, the achievement of which may be influenced by many factors, including gender. ${ }^{1}$ For several decades, the proportion of women enrolling in medical schools in the United States (US) has increased, surpassing men in $2017 .{ }^{2}$ Gender as a

Correspondence: Roman Schumann, MD, FASA

Department of Anesthesiology, Critical Care and Pain Medicine, VA Boston Healthcare System

West Roxbury, Massachusetts, 02132

roman.schumann@va.gov factor of equality and equal opportunity has received increasing attention in academic medicine. ${ }^{3}$ For example, in anesthesiology training programs accredited by the US Accreditation Council for Graduate Medical Education (ACGME), women comprised $34.4 \%$ of residents and fellows and $25.5 \%$ of practicing anesthesiologists in 2017.4 Bissing et $\mathrm{al}^{5}$ reported that between 2006 and 2016, the percentage of women academic anesthesiologists increased from $29 \%$ to $36 \%$; yet, the percentage of anesthesiology department chairwomen remained unchanged. Examining scientific publications as a 
factor for academic advancement in the specialty of anesthesiology in the US, Hurley et al. ${ }^{6}$ found men to be more likely to have published more articles than women, and the number of publications was related to academic rank independent of gender.

The primary purpose of this study was to describe the current distribution of senior academic rank (SAR) between women and men in US anesthesiology training programs. A secondary purpose was to describe how being a woman, and also how departmental and training program factors impact the percentage of SAR as a measure of academic success. As a novel study approach, we used information that was publicly available on the Internet for data collection.

\section{METHODS}

In this observational study, we collected and analyzed data between October 2016 and January 2017. Each website of the 131 US anesthesiology programs accredited by the ACGME and registered with the National Resident Matching Program was accessed for data collection. SAR was defined as titles of either associate professor or professor, irrespective of modifiers such as "clinical," "tenured," or other terms. Programs were excluded if the website did not have an individual faculty roster or their associated academic ranking. Among 131 programs, $21(16 \%)$ did not provide faculty academic ranks.

Data collected included gender, academic rank (professor, associate professor, assistant professor, clinical instructor), fellowship training status, number of faculty and residents per year of training, number of faculty who graduated from American and foreign medical schools, number of fellowship programs (accredited and non-accredited) offered, and the program's geographic location.

To determine faculty gender, 1 study team member (FZ) and 2 research assistants examined faculty names and/or images on the program websites. The study team estimates this method allowed gender assertion for $95 \%$ of faculty. For the remaining approximately $5 \%$, a next step was to assess gender indicators (eg, the words "his" or "her") on a faculty's personal web page or their curriculum vitae when available. If unsuccessful, the investigators would search information from the faculty's former residency training or fellowship program website. In case of continued uncertainty, professional websites such as Doximity and Linkedln were accessed, and the Google search engine was used to find a faculty name linked with the term "anesthesiologist" and a training program. As a last resort, we queried Google with the question "What is the gender of [name]? ". Using this approach, we were able to assign all faculty to either female or male gender, although we did not specifically track the exact number of instances with uncertainty.

Fellowship training status of faculty was determined by program website information and the faculty curriculum vitae. No such information was available on the sites of 15 of the 110 programs included in the final analysis.

Graduation from an American or foreign medical school was available in all instances.

The US Census categories Northeast, South, Midwest, and West were used to allocate program geographic location. ${ }^{7}$

For reporting this manuscript, we followed the STROBE checklist for cross-sectional observational studies (best fit). ${ }^{8}$ This study met the criteria for exemption by the local Institutional Review Board.

\section{Statistical analysis}

We calculated percentages of gender differences among professors and associate professors, and SAR (professors and associate professors combined) and used the independent $t$-test for comparison. Histograms served to confirm the normality of the continuous variables.

To determine the association of female gender and SAR, we performed univariate logistic regression, as well as multivariate logistic regression adjusting for the number of faculty, residency program size, resident-to-faculty ratio, geographic location, proportionate gender difference per program, fellowships offered, and geographic location, such that the Northeast served as the indicator variable (=1) for comparison.

Factors emerging as significant $(P \leq .05)$ in the univariate analysis were used in the multivariate model to determine associations with SAR. Where appropriate, confidence intervals $(\mathrm{Cl})$ and odds ratios (OR) further describe the data. The Statistical Package for the Social Sciences version 24.0 for 
Windows (SPSS IBM, Chicago, IL, 2016) was used for all analyses.

\section{RESULTS}

Among all 131 programs, 6 (4.5\%) did not have any usable faculty information on the program's website. The number of program faculty and extraction of gender information was possible for 125 programs $(95.5 \%)$, and complete study information was available for 110 programs (84\%) that constituted the final cohort for analysis (Figure 1). These 110 programs represented a combined 7993 faculty. Among these, $5243(66 \%)$ faculty were men and 2750 (34\%) were women.

Figure 2 shows the professorial rank distribution of anesthesiology teaching faculty from the analyzed programs, including by gender subsets $(P \leq .005$ for all). Figure 3 captures the proportional rank differences within gender category. Among the faculty, $18.3 \%(95 \% \mathrm{Cl}, 15.6-21.3)$ of women and $27.6 \%(95 \% \mathrm{Cl}, 24.7-31.3)$ of men had a SAR $(P$ $<.001)$.

Fellowship training data existed for 6952 faculty (87\% of the study cohort; 4571 men and 2381 women), and 3814 (54.9\%) were fellowship trained. Of these, 2541 (55.6\%) were male faculty and 1273 $(53.5 \%)$ were female faculty. The average proportion of faculty who graduated from an American medical school was $59 \%$.

\section{Univariate analysis}

The analysis of gender and academic success showed that female gender had an OR of 0.587 $(95 \% \mathrm{Cl}, 0.523-0.658 ; P<.001)$ or a $41.3 \%$ lower likelihood to advance to a SAR compared to male gender. Faculty fellowship training increased the odds for SAR to $65.4 \%$ (OR 1.654, 95\% Cl 1.4811.848; $P<.001)$. For every 1 fellowship program offered by an anesthesiology training program, the odds for faculty SAR increased by $3.6 \%$ (OR 1.036, $95 \% \mathrm{Cl} 1.015-1.058 ; P=.001)$. The number of residents in a program was not a significant factor (OR 1.004, 95\% Cl 0.996-1.011; $P=.33$ ), but the odds for SAR notably increased with a greater resident-to-faculty ratio (OR $2.760,95 \% \mathrm{Cl} 1.642-$ 4.638; $P<.001)$.

A higher number of faculty in the department reduced the odds for SAR by $0.01 \%$ (OR 0.999, $95 \% \mathrm{Cl} 0.998-1.0 ; P=.015)$. The proportion of faculty who graduated from an American medical school was not a significant factor for SAR status (OR 0.872, 95\% Cl 0.736-1.034; $P=.87$ ).

Compared to the Northeast, the odds of advancement to SAR in the Midwest was not significantly different (OR $0.954,95 \% \mathrm{Cl}$ 0.8221.109; $P=.54$ ), but odds were significantly higher in the West (OR 1.483, 95\% Cl 1.237-1.751; $P<$ .001 ) and South (OR 1.67, 95\% Cl 1.308-1.717; $P$ $<.001)$.

\section{Multivariate analysis}

In the multivariate model adjusting for gender proportions, faculty size, number of fellowships, resident-to-faculty ratio, and geographic location, women had an OR of $0.553(95 \% \mathrm{Cl} 0.492-0.622$; $P<.001$ ) or $42.7 \%$ lower odds of having a SAR compared to men. The total number of faculty, the departmental gender proportion, the number of fellowships offered, and the geographic location remained significant factors for faculty SAR independent of gender (Table 1).

\section{DISCUSSION}

Our results show that one-third of anesthesiology faculty were women during the study period. Proportionately fewer women had a SAR, which was even more pronounced for professor vs associate professor rank. Being a woman was associated with significantly lower odds for SAR.

The reasons for these findings are likely complicated, multifactorial, and difficult to conclusively examine. Not specific to anesthesiology but pertaining to the broader academic medical community, inconsistent promotion processes and a lack of oversight are contributing factors. ${ }^{9}$ Likewise, Carr et $\mathrm{al}^{10}$ examined barriers to career advancement for women in science and offered best practices for 6 important themes, concluding that a cultural transformation is necessary to address the issues. A favorable academic climate for women has been defined as one in which formal and informal institutional attitudes and strategies promote equality in the workplace. ${ }^{11}$ Some authors conclude that the current climate does not adequately support women. ${ }^{12-14}$ Raj et al. ${ }^{15}$ recently provided a detailed examination of gender and social equality, with recommendations for improvement specifically based on US data for academic medicine. 
Figure 1

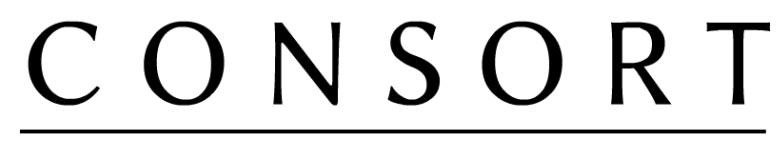

TRANSPARENT REPORTING Of TRIALS

\section{CONSORT Study Flow Diagram}

\section{Enrollment}

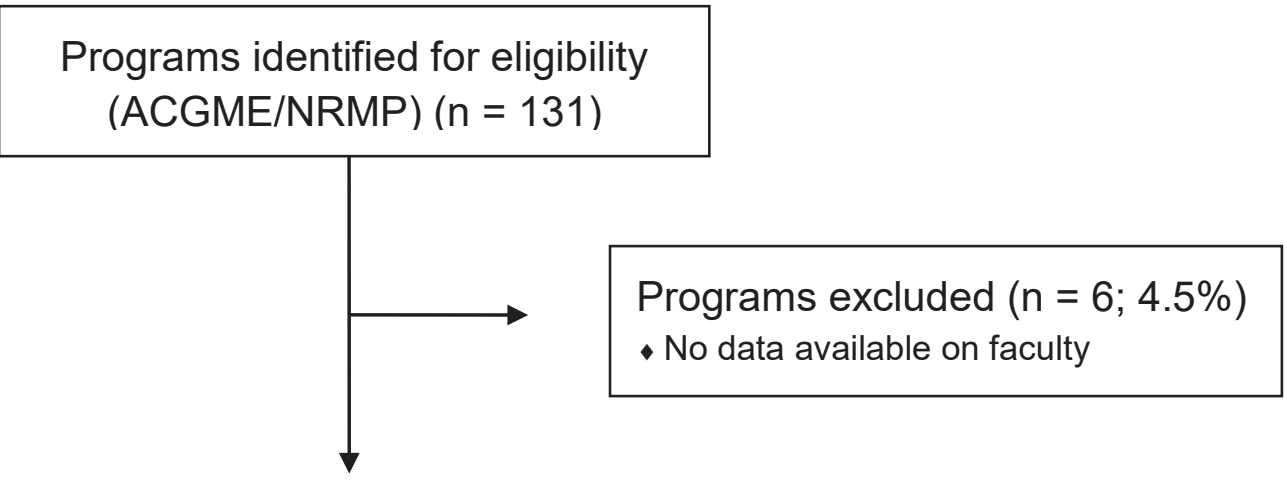

$$
\begin{aligned}
& \text { Programs with faculty data }(\mathrm{n}=125 ; 95.5 \%) \\
& \begin{array}{cl}
\text { Total faculty } & \mathrm{n}=8647 \\
\text { Men } & \mathrm{n}=5673(65.6 \%) \\
\text { Women } & \mathrm{n}=2974(34.4 \%)
\end{array}
\end{aligned}
$$

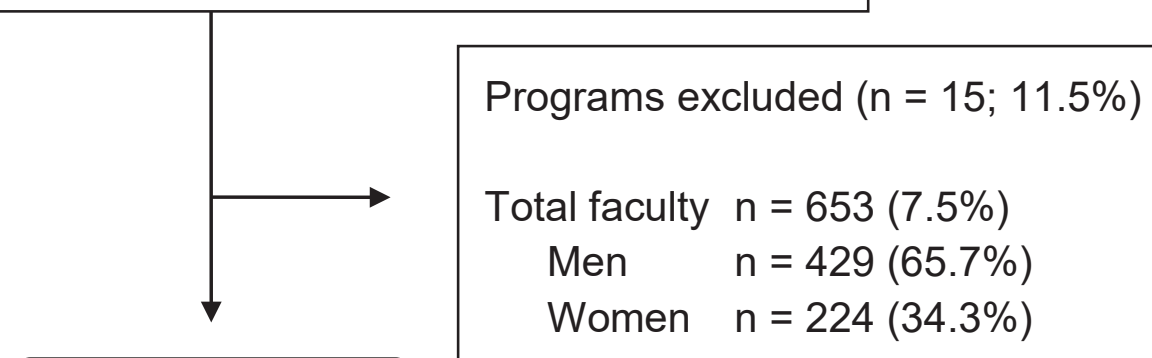

Allocated to final analysis with complete data: 110 programs $(84.0 \%)$

Total faculty $n=7993$ (92.4\% of faculty in 125 programs with faculty information)

Men $\quad n=5243(65.6 \%$ of final total faculty available for analysis)

Women $\quad n=2750(34.4 \%$ of final total faculty available for analysis)

Figure 1. Consort Study Flow Diagram. ACGME, Accreditation Council for Graduate Medical Education; NRMP, National Resident Matching Program. 


\section{Figure 2}

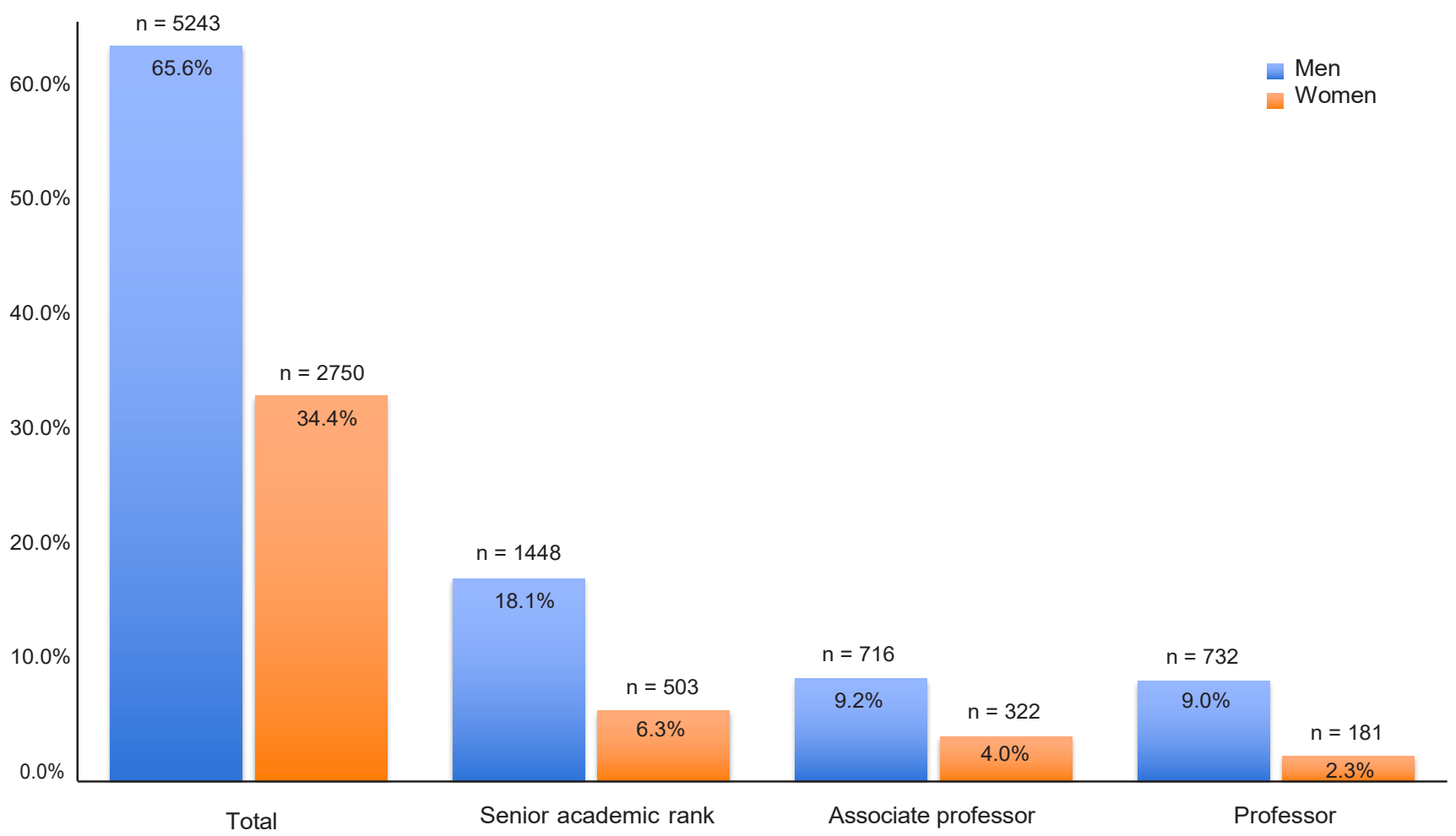

Figure 2. Absolute Differences in the Proportion of Men and Women by Senior Academic Rank in US Anesthesiology Training Programs. Among US academic anesthesiology faculty, there were approximately half as many women as men. A senior academic rank was held by a disproportionately lower percentage of women than men.

\section{Figure 3}

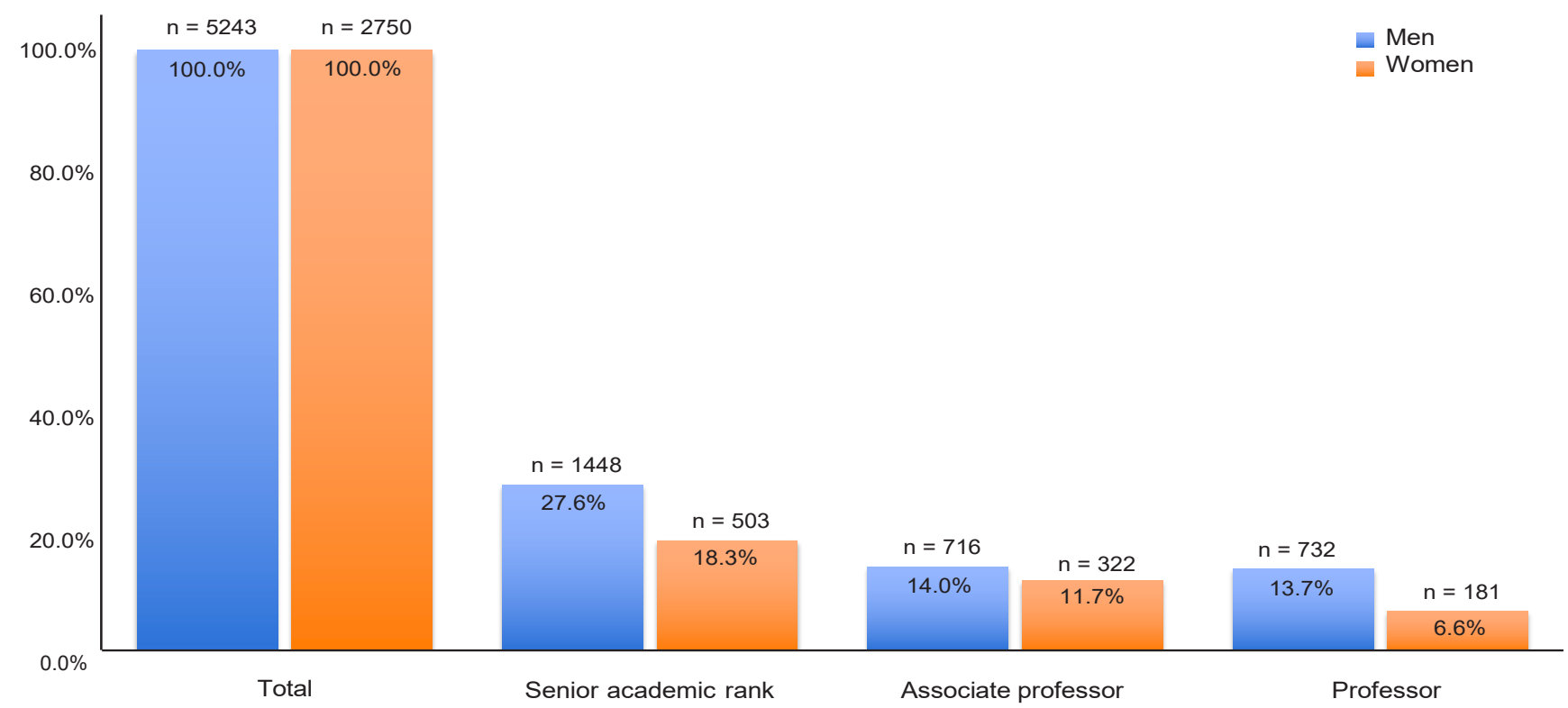

Figure 3. Senior Academic Rank within Male and Female Gender of Faculty in US Anesthesiology Training Programs. Among women faculty, significantly fewer held a senior academic rank compared to men faculty

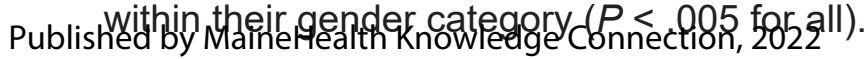


Table 1. Multivariate Analysis of Factors for Faculty Who Hold Senior Academic Rank in US Academic Anesthesiology Programs

\begin{tabular}{llll}
\hline & OR & $\mathbf{9 5 \%} \mathbf{C l}$ & $\boldsymbol{P}$ value \\
\hline Gender (women compared to men) & 0.553 & $0.492-0.622$ & $<.001$ \\
Faculty number & 0.995 & $0.993-0.997$ & $<.001$ \\
Absolute difference in gender proportions & 0.656 & $0.473-0.911$ & .012 \\
Number of fellowships offered & 1.133 & $1.092-1.176$ & $<.001$ \\
Resident-to-faculty ratio & 1.386 & $0.679-2.826$ & .370 \\
Geographic location (compared to Northeast) & & & \\
$\quad$ West & 1.247 & $1.061-1.465$ & .008 \\
$\quad$ Midwest & 0.811 & $0.692-0.950$ & .010 \\
$\quad$ South & 1.497 & $1.308-1.714$ & $<.001$ \\
\hline Abbreviation
\end{tabular}

Abbreviations: $\mathrm{Cl}$, confidence interval; OR, odds ratio.

The European perspective on gender equality was comprehensively discussed, and specific gender equality plans for medicine were proposed to improve a situation similar to that in the US. ${ }^{16}$ The European Society of Intensive Care Medicine published a statement paper in 2019 that covers a way forward to address equality among sexes, gender identities, sexual orientations, ethnicities, cultures, socioeconomic status, and multiprofessionalism. ${ }^{17}$

Gender equality, faculty, and student diversity are topics of increasing interest in academic medicine, including in anesthesiology. Program data that was publicly available on the Internet allowed us to describe and analyze the gender composition of US anesthesiology training programs, SAR as a surrogate for academic success, and associated factors. A wealth of information was available, extending traditional data sources for studies such as ours and could also apply to specialties other than anesthesiology. Internet-based data may allow international comparisons on this topic, which can be hypothesis-generating when more accurate data sources comparable to that from the American Association of Medical Colleges are not available. However, when interpreting these results, we acknowledge that the data are subject to significant confounding (outdated or missing data) because there is no formal accountability for departments to publish this information online.

Our study limitations include lack of data for 21 programs, the possibility of inaccurate or outdated information, a binary gender definition, and dependence on the available data that focus https://knowledgeconnection.mainehealth.org/jmmc/vol4/iss1/5 on a fraction of elements important for academic success. For example, data on faculty age, duration of practice, family status of faculty, and other more detailed factors were not available but may be important. For study purposes, the gender of faculty was assigned using name and image indicators by a study team member aided by 2 research assistants, which may have led to some incorrect classifications.

\section{CONCLUSIONS}

A proportionate gender imbalance toward greater male faculty exists in US anesthesiology training programs, and female gender reduces the odds for academic success. Independent of gender, we found that a greater number of fellowships in a program and faculty fellowship training increased the odds for SAR, whereas a larger department and having fewer women decreased these odds. Residency size and the resident-to-faculty ratio were not important factors for academic success. Interestingly, the geographic location of programs was an influencing factor for having a SAR.

Our results mirror findings of similar investigations and provide new data on factors difficult to modify but important to consider in the pursuit of possible solutions.

\section{REFERENCES}

1. Carr PL, Raj A, Kaplan SE, Terrin N, Breeze JL, Freund KM. Gender differences in academic medicine: retention, rank, and leadership comparisons from the National Faculty Survey. Acad Med. 2018;93(11):1694-1699. doi:10.1097/ ACM.0000000000002146 


\section{Lee et al.: Gender and academic ranks in US anesthesiology programs}

2. Table A-1: U.S. Medical School Applications and Matriculants by School, State of Legal Residence, and Sex, 2018-2019. Association of American Medical Colleges. Accessed November 18, 2018. https://www.aamc.org/download/321442/data/factstablea1.pdf

3. Richter KP, Clark L, Wick JA, et al. Women physicians and promotion in academic medicine. $N$ Engl $J$ Med. 2020;383(22):2148-2157. doi:10.1056/NEJMsa1916935

4. Physician Specialty Data Report: Active Physicians by Sex and Specialty, 2017. Association of American Medical Colleges. Accessed November 18, 2018. https://www.aamc.org/data/ workforce/reports/492560/1-3-chart.html

5. Bissing MA, Lange EMS, Davila WF, et al. Status of women in academic anesthesiology: a 10-year update. Anesth Analg. 2019;128(1):137-143. doi:10.1213/ANE.0000000000003691

6. Hurley RW, Zhao K, Tighe PJ, Ko PS, Pronovost PJ, Wu CL. Examination of publications from academic anesthesiology faculty in the United States. Anesth Analg. 2014;118(1):192-199. doi:10.1213/ANE.0b013e3182a91aa9

7. Census regions and division of the United States. United States Census Bureau. Accessed December 10, 2018. https://www2. census.gov/geo/pdfs/mapsdata/maps/reference/us_regdiv.pdf

8. Enhancing the quality and transparency of health research. Equator Network. Accessed November 12, 2021. https://www. equator-network.org/reporting-guidelines/strobe/

9. Murphy M, Callander JK, Dohan D, Grandis JR. Women's experiences of promotion and tenure in academic medicine and potential implications for gender disparities in career advancement: a qualitative analysis. JAMA Netw Open. 2021;4(9):e2125843. doi:10.1001/jamanetworkopen.2021.25843
10. Carr PL, Helitzer D, Freund K, et al. A summary report from the Research Partnership on Women in Science Careers. J Gen Intern Med. 2019;34(3):356-362. doi:10.1007/s11606-018-4547-y

11. Carr PL, Gunn CM, Kaplan SA, Raj A, Freund KM. Inadequate progress for women in academic medicine: findings from the National Faculty Study. $J$ Womens Health (Larchmt). 2015;24(3):190-199. doi:10.1089/jwh.2014.4848

12. Shollen SL, Bland CJ, Finstad DA, Taylor AL. Organizational climate and family life: how these factors affect the status of women faculty at one medical school. Acad Med. 2009;84(1):8794. doi:10.1097/ACM.0b013e3181900edf

13. Pololi LH, Jones SJ. Women faculty: an analysis of their experiences in academic medicine and their coping strategies. Gend Med. 2010;7(5):438-450. doi:10.1016/j.genm.2010.09.006

14. Isaac $C$, Lee $B$, Carnes M. Interventions that affect gender bias in hiring: a systematic review. Acad Med. 2009;84(10):1440-1446. doi:10.1097/ACM.0b013e3181b6ba00

15. Raj A, Kumra T, Darmstadt GL, Freund KM. Achieving gender and social equality: more than gender parity is needed. Acad Med. 2019;94(11):1658-1664. doi:10.1097/ACM.0000000000002877

16. Hasebrook J, Hahnenkamp K, Buhre WFFA, et al. Medicine goes female: protocol for improving career options of females and working conditions for researching physicians in clinical medical research by organizational transformation and participatory design. JMIR Res Protoc. 2017;6(8):e152. doi:10.2196/ resprot. 7632

17. Weiss B, Task Force and Working Groups for Diversity and Equality of the ESICM. Statement paper on diversity for the European Society of Intensive Care Medicine (ESICM). Intensive Care Med. 2019;45(7):1002-1005. doi:10.1007/s00134-01905606-0 